\title{
Reports of AIDS from the Lady Ridgeway Hospital for Children
}

\author{
B J C Perera ${ }^{1}$
}

(Index words: Paediatric HIV/AIDS, lack of antiretroviral drugs)

\section{Background}

Human immunodeficiency virus (HIV) infection and acquired immunodeficiency syndrome (AIDS) were first detected in Sri Lanka in 1986 (1). The WHO and UNAIDS estimate that about 200 children are presently living with the disease in the country (2). This article presents the first documentation of paediatric HIV infection and AIDS from the Lady Ridgeway Hospital for Children (LRHC).

\section{Case 1}

A 4-month old baby was transferred to LRHC on 23 December 1999 with a 7-day history of fever, cough and difficulty in breathing. She had clinical evidence of pneumonia and septicaemia, extensive oral thrush, and was admitted to the intensive care unit. The child was mechanically ventilated and treated with penicillin, cefotaxime and clarithromycin. The serology was positive for HIV in the child as well as in the parents. The father is a long distance driver and mother had worked in the middle east for 5 years before marriage. Antiretroviral drugs were not available at LRHC. The child steadily deteriorated and died 27 days after admission. Consent for post-mortem examination was refused.

\section{Case 2}

A 2-year old boy was transferred to LRHC on 15 March 2000 for investigation of unresolving pneumonia, cardiac failure and failure to thrive. He had extensive mucous membrane candidiasis, was grossly underweight, stunted, dyspnoeic and had clinical evidence of cardiomegaly, cardiac failure and bronchopneumonia. Chest xray showed reticulonodular shadowing and echocardiography revealed a dilated cardiomyopathy with poor ventricular function. Further investigations showed positive serology for HIV and active pulmonary tuberculosis. Both parents were HIV positive, and the father had active pulmonary tuberculosis. The child was treated with cotrimoxazole, cefuroxime, cloxacillin, rifampicin, isoniazid, pyrazinamide and cardiac failure therapy. Antire-troviral drugs were not available but he showed steady improvement. However, the parents removed him against medical advice 23 days after admission. He had subse-quently been readmitted to Gampaha Base Hospital in a mori-bund state 2 weeks later, and had died soon after admission. A post-mortem examination had not been performed.

\section{Case 3}

A baby born at Castle Street Maternity Hospital, Colombo, on 16 February 2000 was referred to LRHC for continued observation and care. His mother was HIV positive and died during the perinatal period of a severe pneumonia. The father had died of pyogenic meningitis 3 months before delivery of the baby, but his HIV status is not known. The baby was normal at the initial examination and was being cared for by the maternal aunt. His serology was strongly positive for antibodies to HIV and also for HIV antigens, confirming active infection by the virus. Antiretroviral drugs were not available, and he was treated with cotrimoxazole as prophylaxis for Pneumocystis carinii infection. He was on formula feeds and thrived normally up to the age of 5 months. Routine immunisations were done up to that time.

At the age 5 months he started to lose weight and developed generalised lymphadenopathy. He developed repeated lower respiratory tract infections which were increasingly difficult to control. At the age of 6 months he developed hepatosplenomegaly and continued to be admitted repeatedly with episodes of bronchopneu-monia. At the age of 8 months he was admitted with a severe pneumonia and septicaemia to which he succumbed within 24 hours of admission. Consent for post-mortem examination was refused.

\section{Discussion}

These three children had contracted HIV infection from their mothers during pregnancy. All of them presented with severe respiratory infections including one instance of pulmonary tuberculosis. Dilated cardiomyopathy was also found in one of them. These are well known presentations of HIV and AIDS in childhood.

Approximately $10 \%$ of all HIV-infected patients, the "rapid progressors", evolve into AIDS within the first 2 to 3 years of infection (3). The biological characteristics that induce rapid progression are not clearly known. The proportion of rapid progressors is higher in children. Thus paediatric AIDS is often the first indication of the disease in a community as it tends to present earlier than in adults. A high index of suspicion is necessary to detect cases of HIV infection in children. Surveillance of certain high risk groups together with testing of pregnant women would be useful in case detection.

\footnotetext{
${ }^{1}$ Paediatrician, Lady Ridgeway Hospital for Children, Colombo 8. (Received 18 June and accepted 29 June 2002. Correspondence BJCP email: bjep@sltnet.lk telephone +94 1 863265. Competing interests, none declared).
} 
The non-availability of antiretroviral drugs was a major constraint to optimum treatment of the patients reported here. If available these drugs could be used to prevent mother-tochild transmission of the disease as well. The drugs prevent such transmission in a significant proportion and is the most cost-effective use of these drugs at the present time.

\section{References}

1. Statistics of the STD/AIDS Control Programme, Sri Lanka, 2002 (personal communication).

2. http://www.unaids.org/hivaids/statistics/fact_sheets/pdfs/ Srilanka_en.pdf (Accessed 25-5-2002).

3. Khanlou H, Salmon-Ceron D, Sicard D. Characteristics of rapid progressors in HIV infection. Annals of Internal Medicine 1997; 148: $163-6$. 